\title{
Zygomycetes-based biorefinery: Present status and future prospects
}

Jorge A. Ferreira ${ }^{1}$, Patrik R. Lennartsson ${ }^{1}$, Lars Edebo ${ }^{2}$, Mohammad J. Taherzadeh ${ }^{1 *}$

${ }^{1}$ School of Engineering, University of Borås, SE 501 90, Borås, Sweden

${ }^{2}$ Department of Clinical Microbiology, University of Gothenburg, SE 41346 Gothenburg, Sweden

*Corresponding author: Mohammad J. Taherzadeh

Tel: $+46-33-4355908$

Fax: $+46-33-4354008$

Email: Mohammad.Taherzadeh@hb.se 


\begin{abstract}
Fungi of the phylum Zygomycetes fulfil all requirements for being utilized as core catalysts in biorefineries, and would be useful in creating new sustainable products. Apart from the extended use of zygomycetes in preparing fermented foods, industrial metabolites such as lactic acid, fumaric acid, and ethanol are produced from a vast array of feedstocks with the aid of zygomycetes. These fungi produce enzymes that facilitate their assimilation of various complex substrates, e.g. starch, cellulose, phytic acid, and proteins, which is relevant from an industrial point of view. The enzymes produced are capable of catalysing various reactions involved in biodiesel production, preparation of corticosteroid drugs, etc. Biomass produced with the aid of zygomycetes consists of proteins with superior amino acid composition, but also lipids and chitosan. The biomass is presently being tested for animal feed purposes, such as fish feed, as well as for lipid extraction and chitosan production. Complete or partial employment of zygomycetes in biorefining procedures is consequently attractive, and is expected to be implemented within a near future.
\end{abstract}

Keywords: Biorefinery; Zygomycetes; Metabolites; Enzymes; Cell mass 


\section{Introduction}

Microbial fermentation has been used since ancient times. During the last century, however, petroleum-based refineries have prevailed over microbial routes for production of fine chemicals, due to the abundance and low cost of crude oil. Due to oil depletion forecasts, global warming, and the steadily increasing amount of waste products, the situation is now changed. Sustainable development is presently on the agenda, and great efforts have been made by seeking to replace oil-based refineries with biorefineries based on renewable feedstocks. Using filamentous fungi, with diverse and expanding products, constitute an important contribution to this development. Fermentation processes for the production of organic acids, antibiotics, enzymes, food components, and other miscellaneous products have already been applied (Gibbs et al., 2000).

Given their structural and physiological properties, zygomycetes are receiving increased attention within the biotechnological field. They are already well known due to their extended use in China and Southeast Asia, for the production of fermented foods such as tempe and tofu (Lennartsson, 2012). The fungi have in recent times been investigated and used for production of a wide range of metabolic products. Examples include organic acids, enzymes, and biofuels such as bioethanol and biodiesel. In addition, the zygomycetes biomass contains beneficial quantities of proteins, lipids, amino acids, chitosan, and chitin. Thus, the biomass is envisaged for production of animal feed, human food, and chitosan. Zygomycetes are able to grow on a large variety of carbon sources at different temperatures, oxygenation rates, and $\mathrm{pH}-\mathrm{values}$. They are amylolytic, and able to consume pentose sugars. They are also able to perform simultaneous saccharification and fermentation (SSF) of starch materials.

Contemplating the minimal requirements of growth, the easy recovery of fungal mycelium, and the variety of feasible co-products, zygomycetes biomass holds the capacity of playing an 
important role in the future establishment of economically attractive zygomycetes-based biorefineries, and may well be exploited in already established industrial processes to enhance profitability.

The aim of the present review is to gather the different biotechnological applications of zygomycetes holding the highest potential for a biorefinery (Fig. 1), which mainly refers to flexibility in terms of the raw materials to be used, and their capability of producing metabolites, enzymes, and biomass.

\section{Zygomycetes as core catalysts in biorefineries}

The kingdom Fungi is considered to comprise four phyla; Chytridiomycota, Zygomycota, Ascomycota, and Basidiomycota. Zygomycota is divided into two classes, Trichomycetes and Zygomycetes, which are found worldwide as saprophytes growing on dead organic matter. Zygomycetes have long been used in food production. However, they have also been observed to be pathogens of plants, animals, and other fungi, and suitable strains must hence be selected (Lennartsson, 2012).

Zygomycetes are versatile filamentous fungi with well demonstrated growth ability in a vast array of culture media. The medium requirements are generally characterized as inexpensive and unspecific, and include, apart from some salts, a variety of nitrogen and carbon sources (Zhang et al., 2007), the range of the latter being wide and expanding, mostly due to the variety of enzymes carbon sources produce (Fig. 1). Glucose has been the first choice as carbon and energy source. However, some strains are able to consume more complex sugars, such as the disaccharides sucrose and lactose (Guo et al., 2010; Vamvakaki et al., 2010). Valorization of cheese whey, a lactose-containing dairy waste, as a renewable substrate for 
zygomycetes has also been investigated (Vamvakaki et al., 2010). Furthermore, these fungi have, as amylase producers, the prerequisites for simultaneous saccharification and fermentation (SSF) of starchy materials. SSF has been widely examined due to its capacity to enhance process productivity, reduce the reactor volume required, and hence also capital costs. Starchy crops, such as barley, cassava, corn, oats, and rice, have been used as carbon sources for zygomycetes in the production of lactic acid (Zhang et al., 2007). Koutinas et al. (2007) designed an oat-based biorefinery for production of lactic acid and various valueadded co-products, including $\beta$-glucan and an anti-irritant solution. Due to their renewable character, abundance, and cheap price, lignocellulosic materials are also promising feedstocks for biotechnological processes (Zhang et al., 2007). A wide variety of lignocellulosic materials, providing cellulosic and hemicellulosic feedstocks, have been evaluated for production of value-added products, using zygomycetes (Fig. 1). Corn straw and wood hydrolysates have for instance been examined for production of fumaric acid and ethanol, respectively, while wheat bran, cellulose, and xylan have been analysed for production of cellulases and xylanases (Lennartsson, 2012; Xu et al., 2010). Valorization of using spent sulphite liquor, a waste hemicellulosic product from paper pulp mills, for producing highvalue zygomycetes biomass for fish feed as well as chitosan, has also been carried out (Bankefors et al., 2011; Lennartsson, 2012; Mydland et al., 2007). Although lignocellulosic materials have been scrutinized for ethanol production for decades, developing a feasible commercial process has not yet been accomplished. In a facility using lignocellulosic materials, the total value might be raised with Zygomycetes producing biomass as a second product (Lennartsson, 2012). At present, agricultural crop-based facilities are being used for ethanol production. The process results in large volumes of low value by-products, thin stillage being a major one. Thin stillage may however be utilized by zygomycetes for cell mass production. The process results in a product enriched with protein (including amino acid 
composition), lipids, and chitosan (van Leeuwen et al., 2012). Zygomycetes are also capable of utilizing lipids and fatty acids. Being lipase producers, zygomycetes have been examined extensively for biodiesel production, using plant oil as well as animal fat as substrates (Ghosh \& Ray, 2011).

In addition to carbon sources, presence of nitrogen in the culture medium is crucial for optimal zygomycetes growth and final product yields. Various inorganic and organic nitrogen sources have been employed. Typically, inorganic nitrogen such as ammonium sulphate and ammonium nitrate has been used, but the organic nitrogen of peptone, urea, yeast extract, corn steep liquor, or even fish protein hydrolysate, may also be used (Vattem \& Shetty, 2002; Zhang et al., 2007). Furthermore, inorganic salts, including $\mathrm{KH}_{2} \mathrm{PO}_{4}, \mathrm{MgSO}_{4}, \mathrm{ZnSO}_{4}, \mathrm{CaCl}_{2}$, and $\mathrm{Fe}_{2}\left(\mathrm{SO}_{4}\right)_{3}$, may also play a significant role for securing optimal fermentation (Lennartsson, 2012; Zhang et al., 2007). Non-expensive feedstocks containing the aforementioned nutrients might reduce the cost and enhance the sustainability of the process. Dairy manure has been used as carbon as well as nitrogen source for fumaric acid production (Liao et al., 2008). In exploiting the ability of zygomycetes to hydrolyse complex macromolecules (Koutinas et al., 2007), oat flour as sole nutrient source for lactic acid production was tested.

Being filamentous fungi, zygomycetes can adopt diverse morphological forms when cultivated in submerged culture. Various factors such as medium composition, inoculum size, $\mathrm{pH}$, temperature, aeration rate, and agitation speed, affect the fungal morphology (Gibbs et al., 2000). They may grow as uniform filaments, evenly distributed throughout the cultivation medium, but also as entangled filaments, in clumps and pellets. The growth mode affects the 
rheological properties of the cultivation medium, and consequently, the overall process performance and final product yields (Gibbs et al., 2000).

The pellet-mode of growth has been dominating in the zygomycetes research, since it results in lower broth viscosity. The possibility of performing high-density cultivation yielding significantly higher productivity has also been a significant factor. However, pellets need to be kept below a critical size to prevent oxygen limitation (Roa Engel et al., 2011), and strategies for controlling the zygomycetes morphology has consequently been developed. After optimizing the medium, Liao et al. (2007) succeeded to cultivate Rhizopus oryzae in pellet-form. This form enhanced the production of lactic as well as fumaric acid in comparison with clump morphology. Zhang et al. (2008) controlled the morphology of R. arrhizus in a continuous stirred-tank reactor (CSTR) by using an acid-adapted preculture approach. Loose small pellets achieved the highest lactic acid production and yield from waste potato starch. Fu et al. (2009) developed a multi-stage preculture strategy in order to control the morphology of R. oryzae in a CSTR. Small fluffy pellets, produced in the third preculture at $\mathrm{pH}$ 3.0, resulted in the highest fumaric acid production. Zhou et al. (2011) controlled the pellet size by varying the initial glucose and peptone concentrations. They observed that cell mass and fumaric acid yield tended to increase with decreasing pellet diameter.

To summarize, the ability to utilize a variety of non-expensive feedstocks for the production of valuable and diverse products (Fig. 1) warrants a high plausibility of zygomycetes being used as a core catalyst in a biorefinery. The capability of simultaneously generating more than one valuable product, e.g. a metabolite and biomass, might in particular have a significant impact on biorefining as a whole. 


\section{Metabolites of Zygomycetes}

The metabolic versatility of zygomycetes makes them well suited for biorefining, and is central to the great research interest. They are reported to be valuable producers of metabolites, mainly lactic and fumaric acid, but also ethanol, from many different substrates, and using various fermentation designs. So far, research has focused primarily on two genera, Rhizopus for production of organic acids, and Mucor for ethanol production. Focus has then been on production of lactic acid, rather than on production of the other metabolites.

In the metabolism of zygomycetes, pyruvate, the final glycolysis product, can be directed into different pathways. The shortest pathway leads directly to the production of lactic acid via lactate dehydrogenase. Another pathway is via the cytosolic reductive TCA, after which fumaric acid is produced, and in which cytosolic fumarase plays an important role. Pyruvate may also be diverted via pyruvate decarboxylase for acetaldehyde production, and be further converted into ethanol by alcohol dehydrogenase (Bai et al., 2004). Consequently, activity and substrate affinity of these enzymes differ, depending on the individual strain, and will thus decide the amounts of metabolites produced (Oda et al., 2002). Stress has been shown to be a requirement for production of organic acids and ethanol. Nitrogen-limiting conditions trigger production of organic acids, whilst oxygen-limiting or anaerobic conditions are necessary for production of ethanol (Lennartsson, 2012). Rhizopus species are divided into lactic and fumaric acid producers, based on the yields of these organic acids (and other metabolites). Interestingly, the Rhizopus species mainly producing lactic acid possess two lactate dehydrogenase genes, ldhA and ldhB, while the fumaric acid producers only had the ldhB gene (Saito et al., 2004). The metabolic differences have been confirmed by a phylogenetic analysis of DNA sequences (Abe et al., 2007). Since the production of organic 
acids is associated with non-growth, a two-stage strategy comprising a cell-growth stage and a production stage needs to be applied. In the cell growth stage, the zygomycetes are kept in a relatively rich medium. In the production stage, the produced biomass is cultivated in a nitrogen-limited medium to promote production of organic acids (Wu et al., 2011). Additional requirements for the organic acid production are oxygen-rich conditions and a neutralizing agent to maintain the $\mathrm{pH}$-value in the medium (Zhang et al., 2007).

\subsection{Lactic acid}

Lactic acid $\left(\mathrm{CH}_{3} \mathrm{CHOHCOOH}\right)$ is the most widely occurring organic acid in nature, and has two known isomers, L(+)-lactic acid and D(-)-lactic acid. Food applications require L-lactic acid, and this isomer is also the preferred monomer for polylactide manufacturing. Other applications for lactic acid are found within the pharmaceutical, leather, cosmetic, chemical, and textile industries. The global market for L-lactic acid has steadily increased, and has been projected to reach 500,000 (metric) tons per year by 2012 (John et al., 2007).

L-lactic acid production by Rhizopus strains has been extensively investigated, seeking to replace the chemical route of fermentation with lactic acid bacteria. Rhizopus species hold an important advantage over bacteria in their ability to produce L-lactic acid in a less expensive medium. Zhang et al. (2007) reviewed the intense research on the development of L-lactic acid production, using free and immobilized Rhizopus cells. The research on this subject is still continuing, and the findings are summarized in Table 1. Glucose is the most studied substrate for L-lactic acid production. However, other production routes, using starchy and lignocellulosic materials as more cost-effective feedstocks, have also been explored (Zhang et al., 2007). In addition to glucose, sucrose is being examined for L-lactic acid production; the yield of $0.81 \mathrm{~g} / \mathrm{g}$ is however difficult to obtain on a regular basis (Guo et al., 2010). In a recent 
study concerning the use of starch-containing substrates, a yield of $0.72 \mathrm{~g} \mathrm{~L}$-lactic acid per gram potato starch was attained, when using Rhizopus in pellet form (Yen \& Lee, 2010).

Glucose, however, has been reported to yield up to $0.90 \mathrm{~g} / \mathrm{g}$ L-lactic acid (Wu et al., 2011), which also surpasses the yield and productivity, using xylose as substrate. Some improvements have nevertheless been made towards xylose conversion into L-lactic acid. Guo et al. (2010) used a new soil-isolated $R$. oryzae strain, obtaining a lactic acid yield of 0.90 $\mathrm{g} / \mathrm{g}$ at a $\mathrm{C} / \mathrm{N}$ ratio of 30 . However, the lactic acid productivity only reached $0.45 \mathrm{~g} / \mathrm{L} / \mathrm{h}$. Further development at laboratory scale is required before valorization of xylose-rich lignocellulosic materials is to be realized for L-lactic acid production. More complex substrates have also been used for lactic acid production. Corncob acid hydrolysate was for instance tested, gaining a lactic acid yield of $0.80 \mathrm{~g} / \mathrm{g}$ sugars (Bai et al., 2008), while Saito et al. (2012) reported a lactic acid yield of only $0.23 \mathrm{~g} / \mathrm{g}$ sugars from simultaneous saccharification and fermentation of wheat straw. Dairy manure appears more promising, probably due to its carbon and nitrogen contents. The crude protein was used as nitrogen source, resulting in approximately $0.60 \mathrm{~g} / \mathrm{g}$ lactic acid (Yao et al., 2010).

Maintaining high yields in the L-lactic acid production processes during long-term fermentations has been hindered by unbalanced fungal growth, relating to nitrogen sources. However, progress has been made. Wu et al. (2011) successfully performed 20 repeated cycles in shake flasks in a continuous stirred-tank reactor. High L-lactic acid yields in the range $0.79-0.90 \mathrm{~g} / \mathrm{g}$ were procured, which was achieved by optimizing the feeding of medium, and by using uniform Rhizopus pellets. 
The intense research towards L-lactic acid production, using Rhizopus species, resulted in a scale-up of the process to $5 \mathrm{~m}^{3}$ airlift bioreactors, using glucose as carbon source. Prospects of designing airlift bioreactors larger than $3000 \mathrm{~m}^{3}$ have previously been provided (Liu et al., 2006). The use of starchy materials for L-lactic acid production in a biorefinery also appears very promising since yields comparable to those from glucose have been obtained.

Lignocellulosic materials, however, require further analyses prior to economical evaluations.

\subsection{Fumaric acid}

Fumaric acid $\left(\mathrm{HO}_{2} \mathrm{CCH}=\mathrm{CHCO}_{2} \mathrm{H}\right)$ is a naturally occurring four-carbon dicarboxylic acid, and has been identified as one of the top ten chemicals to be produced via fermentation on an industrial scale. Due to its non-toxic and non-hygroscopic properties, it is frequently used in food and pharmaceutical industries. Fumaric acid was recently considered for treatment of psoriasis, and as feed additive for cattle (Roa Engel et al., 2008). Its structure with a double bond and two carboxylic groups, makes it furthermore suitable for production of biodegradable polymers, synthetic resins, and intermediates for chemical syntheses (Roa Engel et al., 2008).

Using Rhizopus strains for fumaric acid production has been appraised with the purpose of changing the chemical route from maleic anhydride produced from butane (Roa Engel et al., 2008). Glucose is the major carbon source used in fumaric acid fermentation, yielding up to $0.70 \mathrm{~g} / \mathrm{g}$ fumaric acid, which is lower than the L-lactic acid yields (Huang et al., 2010). However, a two-stage dissolved oxygen control strategy has been applied in an attempt to attain high fumaric acid yield as well as high productivity from glucose. The dissolved oxygen concentration was kept controlled at $80 \%$ during the first $18 \mathrm{~h}$ of fermentation, and then switched to $30 \%$. Although the fumaric acid yield of $0.54 \mathrm{~g} / \mathrm{g}$ was low, it was 
nevertheless the highest yield acquired when using continuous stirred-tank reactors (Fu et al., 2010). It has previously been claimed (Roa Engel et al., 2008) that the low pKa value of fumaric acid $\left(3.03\right.$ at $\left.25^{\circ} \mathrm{C}\right)$ is a property that can be exploited for product recovery. Indeed, when Roa Engel et al. (2011) late in the batch phase switched off the pH control, cell-specific productivity, fumaric acid yield, and fumaric acid titre were not affected, and a $\mathrm{pH}$ of 3.6 was achieved. The $\mathrm{pH}$ control required less inorganic base, and acid recovery should be relatively easy at that $\mathrm{pH}$ value. Ding et al. (2011) demonstrated the relationship between carbonnitrogen ratio, cytosolic fumarase, and fumaric acid titre. In urea of low concentration, the cytosolic fumarase activity increased $300 \%$ and the production of fumaric acid increased up to $40 \mathrm{~g} / \mathrm{L}$.

Studies on lignocellulosic materials for fumaric acid production are scarce (Table 2). Liao et al. (2008) reached a maximum fumaric acid yield of $0.31 \mathrm{~g} / \mathrm{g}$, using acid hydrolysate of manure fibres supplemented with glucose. Xu et al. (2010) applied a two-stage process of corn straw and reported a fumaric acid yield of $0.35 \mathrm{~g} / \mathrm{g}$. The highest yield reported, $0.44 \mathrm{~g} / \mathrm{g}$, was accomplished when Eucalyptus globulus wood hydrolysate was used (Rodríguez-López et al., 2011).

Research on fumaric acid production on a larger scale is missing in literature; Exploring highperformance Rhizopus strains, is still at want, and so is a broader perspective in terms of utilizing alternative substrates. Even so, given its potentials, the production of fumaric acid will most likely trigger intense experimentation in coming years, and its conceivable suitability for application in a biorefinery concept should therefore not be ignored. 


\subsection{Ethanol}

Several Zygomycetes species are known to produce ethanol $\left(\mathrm{CH}_{3} \mathrm{CH}_{2} \mathrm{OH}\right)$ when the oxygen supply is limited. The Mucor genus, and in particular M. indicus, is the most explored group. Taherzadeh et al. (2003) were the first to have fuel ethanol in mind, and reported ethanol yields ranging between 0.20 and $0.37 \mathrm{~g} / \mathrm{g}$ glucose, when using $R$. oryzae. However, aerobic conditions were used at the time and lactic acid was produced as well, limiting the ethanol yield. Millati et al. (2005) compared the Zygomycetes strains R. oryzae, Mucor corticolous, $M$. hiemalis, and $M$. indicus, reporting yields of 0.37-0.43 g ethanol/g glucose under aerobic conditions. The same strains produced ethanol from xylose, yielding $0.15-0.28 \mathrm{~g} / \mathrm{g}$. No ethanol production was reported when using Rhizomucor pusillus or Rhizomucor miehei. Optimization of the growth conditions for M. indicus resulted in ethanol yields of up to 0.46 g/g glucose in anaerobic cultivations (Sues et al., 2005). Most recently, edible zygomycetes were isolated from tempe, a traditional fermented dish in Indonesia, which resulted in 32 isolates with ethanol yields of 0.26-0.41 g/g glucose (Wikandari et al., 2012). Two of the isolates in this study, tentatively identified as belonging to the Rhizomucor genus, were grown under micro-aerobic conditions, producing ethanol from glucose with yields of 0.46-0.47 g/g.

Zygomycetes have also been used for fermentation of lignocellulosic hydrolysates into ethanol. Taherzadeh et al. (2003) pioneered the current research by using $R$. oryzae for ethanol production from spent sulphite liquor. The yield, however, left room for improvement. Only $0.16 \mathrm{~g}$ ethanol/g sugar was produced. Significantly higher yields were achieved by $M$. indicus and $M$. hiemalis from dilute-acid hydrolysate, mainly from spruce; both species reached an ethanol yield of $0.44 \mathrm{~g} / \mathrm{g}$ sugar (Millati et al., 2005). Furthermore, $M$. indicus produced ethanol from orange peel hydrolysate (based on $12 \%$ solids) under limited aerobic conditions and without detoxification, with a yield of $0.40 \mathrm{~g} / \mathrm{g}$ hexoses (Lennartsson, 
2012). No other organism has been reported to be able to grow, or to remain metabolically active, under those conditions. The dimorphic behaviour of $M$. indicus, i.e. its ability to grow in either a yeast-like or a filamentous mode, depending on growth conditions, and whether the mode affects the ethanol production, has also been investigated. No measurable differences were however detected (Lennartsson, 2012).

Although zygomycetes have been explored for fuel ethanol production for a decade with promising results, no scale-up is as yet reported. The reason is probably the focus towards $2^{\text {nd }}$ generation biofuels, whose realization has met with difficulties. The process would probably stand a better chance if a starch or sugar based substrate were used. However, this would require a replacement of the core of an already functioning and well-known industrial process, with a novel biorefinery process. If the achievable economical benefits are sufficiently large to overcome the risks involved, remains to be seen.

\section{Enzymes}

Zygomycetes fungi are the source of a great diversity of enzymes (Table 3). Ghosh and Ray (2011) reviewed the enzymatic characteristics of $R$. oryzae, and their commercial potential. Reasonably, behind the high ability of Zygomycetes fungi to assimilate a large variety of substrates, lies the capacity to produce different hydrolytic enzymes, such as those needed for the degradation of plant carbohydrates, including amylases, cellulases, and xylanases, but also proteases and lipases, and the isolation, purification, and application of these fungal enzymes in different relevant industrial processes, have been extensively pursued. 


\subsection{Amylases}

The production of amylases and glucoamylases enables the zygomycetes to carry out simultaneous saccharification and fermentation (SSF) of starch-based materials, without a need for adding extra enzyme. Amylases are intensively applied within food industries to obtain glucose, and to manufacture glucose syrup for the pharmaceutical, beer, and beverage industries (Peixoto-Nogueira et al., 2008). Actually, in industrial utilization, the conversion of starch into glucose syrups by glucoamylase from Rhizopus and Aspergillus is well established (Chou et al., 2006). Clearly, amylases also play crucial roles in the starch-based ethanol production field. Rhizopus strains produce amylases when cultivated in agricultural commodities, including barley, corn, oats, rice, and cassava, or in starch (Ghosh \& Ray, 2011). Peixoto-Nogueira et al. (2008) observed amylase production by Rhizopus microsporus var. rhizopodiformis in solid-state fermentation, using a mixture of wheat bran, corncob, starch, and saline solution. $R$. oryzae isoamylase was capable of using starch-containing waste food-stuffs. These included rice extract and bred dust, as well as soluble potato starch and various domestic starchy effluents, including arrowroot, tamarind kernel, tapioca, and oat (Ghosh \& Ray, 2011).

In conclusion, with reference to zygomycetes being very potent amylase producers, already involved in industrial processes, it is practically certain that they will continue to be commercially exploited. The potentiality of amylase production playing an important role in biorefining may thus be deemed high.

\subsection{Cellulases and related enzymes}

Zygomycetes fungi have also been screened for production of enzymes exhibiting cellulolytic activities. Saha (2004) demonstrated the presence of a complete cellulase system in Mucor 
circinelloides, comprising endoglucanase, exoglucanase, and $\beta$-glucosidase. Endoglucanases produced by zygomycetes in liquid medium containing chitin or wheat bran, have been investigated and compared to commercial endoglucanases. Potential applications for endoglucanases appear in the brewery industry, where these enzymes lead to lower viscosity (Celestino et al., 2006), and in the textile industry, where they induce higher defibrillation activities on lyocell fabric as well as lower resistance to anionic surfactants and oxidizing agents (Shimonaka et al., 2006). In the animal feed industry, the enzymes showed higher thermostability and activity at $\mathrm{pH}$ 2.6-6.5 than current commercialized $\beta$-glucanases (Boyce $\&$ Walsh, 2007). R. oryzae has also been shown to produce glucanases when grown on a variety of agro wastes, such as dried flower, dried grass, water hyacinth, sugar cane bagasse, or fruit peel (Ghosh \& Ray, 2011). $\beta$-glucosidase activity of species belonging to various zygomycetes genera, e.g. Gilbertella, Mucor, Rhizomucor, and Rhizopus, has been described (Krisch et al., 2010). Takii et al. (2005) tested 12 Rhizopus strains for $\beta$-glucosidase activity in solid-state fermentation, using wheat bran. In one of these strains, $R$. oryzae, the fermentation resulted in a significantly higher enzymatic activity $(0.308 \mathrm{U} / \mathrm{mg}$ of protein) in comparison with the other 11 strains $(<0.05 \mathrm{U} / \mathrm{mg})$. The $\beta$-glucosidase activity of a food grade fungus, Rhizopus oligosporus, grown on cranberry pomace in solid-state fermentation, was enhanced by $\mathrm{NH}_{4} \mathrm{NO}_{3}$ and fish protein hydrolysate, increasing the amounts of extractable phenolics as well as the antioxidant activity. Ellagic acid, a cranberry compound with anti-carcinogenic properties, was enriched to a level of $375 \mathrm{mg} / \mathrm{g}$ dry weight of pomace extract (Vattem \& Shetty, 2002). Shuvaeva and Sysoeva (2010) optimized the production of xylanase from Rhizopus microsporus by employing solid-state fermentation, based on wheat bran, straw, and grain sprouts, and also submerged fermentation, based on xylose, maize extract, and salts. Endo-xylanase production by a $R$. oryzae strain during cultivation in xylan-containing 
agricultural by-products, including wheat straw, cotton residues, hazelnut shells, corn cobs, and oak sawdust, has furthermore been reported (Ghosh \& Ray, 2011).

The production of a variety of cellulases and related enzymes by different zygomycetes has been well demonstrated. However, acknowledging the competition from fungi specialized in cellulose degradation, zygomycetes-based enzymes will probably reach only limited markets. The most feasible enzyme solutions are those with various types of activities and niche markets. Whether there is sufficient incentive for commercial production of zygomycetesbased enzymes, remains to be seen.

\subsection{Pectinases}

Zygomycetes are promising sources of pectinases. Pectin is a polymer of mainly $\alpha-(1,4)-$ linked D-galacturonic acid, some rhamnose, and with side chains rich in arabinose and galactose (Zhang et al., 2005). Maleki et al. (2011) screened 22 zygomycetes isolates from soil for pectinase production, all with positive results. Rhizopus pectinases have been produced in solid culture, using citrus peel of orange, and the crude extract was used for clarifying orange juice (Kareem \& Adebowale, 2007). Rhizopus pectinases have been studied for flax retting, the initial microbiological step in the process of making linen. The retting abilities of different enzyme mixtures are strongly correlated to polygalacturonase activity, and a pure polygalacturonase is able to fulfil efficient retting. Hence, endopolygalacturonases have been isolated from Rhizopus strains and characterized (Zhang et al., 2005). Using oxalic acid or EDTA as chelators, enhanced retting efficiency. Furthermore, the retting efficiency of Rhizopus endopolygalacturonase was comparable to that of the commercial Flaxzyme, a retting mixture comprising xylanase, cellulase, polygalacturonase, and with pectin lyase activities (Akin et al., 2002). The authors scaled up the endopolygalacturonase production to a 
$100 \mathrm{~L}$ bioreactor. Polygalacturonase is also believed to play an essential role in the maceration of mulberry roots by Rhizopus oryzae (Ghosh \& Ray, 2011). Damásio et al. (2011) analysed the production of polygalacturonase and pectin lyase by $R$. microsporus var. rhizopodiformis, grown in more than 20 different carbon substrates, and the highest activity of the two enzymes was detected in medium of lemon peel.

To summarize, zygomycetes fungi appear to be very well suited for production of pectinases, as is confirmed by the presence of these enzymes on the market today, which makes pectinases one of the top products to be derived from a zygomycetes-based biorefinery.

\subsection{Proteases}

Zygomycetes are since long acknowledged as potential sources of proteases. The high protein content and digestibility of fermented foods such as tempe, is related to the proteolytic activity of Rhizopus sp. on soybean seed proteins (Heskamp \& Barz, 1998). Proteases are categorised as alkaline, neutral, or acidic, based on their catalytic mechanism and consequent $\mathrm{pH}$ optimum for activity. Alkaline proteases have extensive applications in washing-materials, whereas acidic proteases are used in food processing. Fungal acidic proteases are considered feasible substitutes for three important proteases involved in food processing, namely, pepsin, rennin, and papain (Ikasari \& Mitchell, 1996). Several aspartic proteases (including pepsins and rennins) have been isolated, purified, and characterized from zygomycetes. Rhizomucor species are good producers of rennins with milk-clotting properties, and have been used in cheese production for a long time. Several Mucor strains are also confirmed to be a promising source of milk-clotting enzymes, with unique technological properties. Their production in submerged culture has been analysed, using casein, gelatine, glucose, and fructose, or more complex substrates such as soybean meal, wheat bran, and cheese whey, as carbon substrates 
(Yegin et al., 2011). In solid-state fermentation studies, the typical source was wheat bran. The production of aspartic proteinases from Mucor sp. has already been scaled up in a continuous stirred-tank reactor (Yegin et al., 2011) of $1.5 \mathrm{~m}^{3}$ capacity. Also R. oligosporus has been reported to hold promise for protease production; it produces a satisfactorily calf rennet substitute at laboratory scale, and does not produce toxins (Ikasari \& Mitchell, 1996). M'hir et al. (2012) produced $R$. oryzae protease in a 20 L continuous stirred-tank reactor after bench-scale optimization, using a wheat gluten and starch-containing medium.

Protease production is widespread among zygomycetes fungi. In view of this and the valuable protease applications within the food industry, the processes for producing these enzymes by using zygomycetes will most certainly continue their straightforward development towards biorefining.

\subsection{Steroid $11 \alpha$-hydroxylases}

The $11 \alpha$-hydroxylation of progesterone by Rhizopus nigricans, an important reaction in the production of therapeutic steroid drugs and hormones, has been utilized in the industry for over half a century (Zhou et al., 2009). Nonetheless, probing cost-effective routes, and economically viable industrial processes for this biohydroxylation, is continuing. The operational activity and stability of the $11 \alpha$-hydroxylation system has been tested with immobilized Rhizopus cells. However, repeated batch processes failed to maintain the hydrolysing activity for long periods (Žnidaršič et al., 1998), prompting Žnidaršič et al. (1998) to perform a detailed analysis of the morphology and physiology of $R$. nigricans pellets, in consecutive cycles. Conversion was optimally achieved in the second cycle, by pellets from the cultivation with the highest agitation and aeration. Zhou et al. (2009) optimized the bioconversion of 16,17 $\alpha$-epoxyprogesterone by means of a uniform design, 
where the medium contained (in g/L): glucose (25), corn steep liquor (22), $\left(\mathrm{NH}_{4}\right)_{2} \mathrm{SO}_{4}(0.1$, and yeast extract (0.86).

Although the use of steroid $11 \alpha$-hydroxylases at industrial scale is well established today, there is indeed room for improving the versatility of the process. Studies on different types of substrates are limited, and so is the knowledge relating to morphological control during continuous cultures. Regardless, considering the value of the process, its potential within biorefining is granted.

\subsection{Phytases}

Phytases are acidic phosphohydrolases that catalyse the release of phosphate from phytate (myco-inositol hexaphosphate), the main form of phosphorous occurring predominantly in cereal grains, legumes, and oilseeds. Interest in phytase production has arisen from its viable application as animal feed supplement; phytase increases the phosphorous availability in phytate-rich feed. This not only aids proper skeleton growth of fed animals, but reduces phosphate pollution as well. Although phytases are produced by a large number of plants, animals, and microorganisms, fungal phytases are preferred in the industry (Pandey et al., 2001).

Phytase production by zygomycetes has mostly been examined in solid-state fermentation. Sesame and groundnut oil cakes, and a mixture of wheat bran and sesame oil cake, were good substrates for phytase production by Mucor racemosus (Roopesh et al., 2006). A mixture of coconut and sesame oil cakes, supplemented with glucose and ammonium nitrate, was also a good solid medium for phytase production by Rhizopus sp. (Ramachandran et al., 2005). Two 
intracellular phytases have recently been isolated from $R$. oligosporus grown in rice flour suspension, and were shown to have broad affinity for various phosphorylated compounds (Azeke et al., 2011).

Research on phytase production has been somewhat limited to solid-state fermentation, where scalability is a problem. Studies addressing phytase production in submerged culture are probably needed to fully evaluate the potential of commercializing the process. However, contemplating its economic potential, if the scalability problems are solved, phytase production could play a central role in a future zygomycetes-based biorefinery

\subsection{Other enzymes and enzymatic co-production}

Tannase, urease, and lipases are other enzymes produced by zygomycetes (Ghosh \& Ray, 2011). Lipases, in particular, are among the most used biocatalysts in organic reactions. Beyond being able to catalyse the hydrolysis of fats and oils, releasing free fatty acids, diacylglycerols, monoacylglycerols, and glycerol, lipases can also catalyse synthetic reactions in non-aqueous media. A relevant practical application of Rhizopus lipases has been the transesterification of plant oils and animal fats, with methanol. The reaction produces fatty acid methyl esters (biodiesel), which has gathered increased interest due to its promise as a green replacement of petroleum based fuels (Ghosh \& Ray, 2011). Another aspect that might be worthy of consideration is the expression of multiple enzymes, occurring in correlation with adequate induction by specific substrates. Oda et al. (2002) claimed for instance that $R$. oryzae grown in potato pulp produced cellulase, pectinase, and amylase, which made it

suitable for L-lactic acid production. Moreover, the capability of $R$. oryzae to use pearled oat 
flour has been utilized for production of glucoamylase, protease, and phytase (Koutinas et al., 2007).

Undoubtedly, zygomycetes fungi are sources of a wide range of enzymes, and the potentiality of these fungi in various industrial areas is far from being fully realized. A full-scale process for biodiesel production based on lipase-producing zygomycetes might well be conceivable in a near future. The process would be particularly interesting if integrated with a biorefinery concept.

\section{Zygomycetes biomass}

\subsection{Composition}

Zygomycetes have attracted great interest within science concerning their biomass composition. The recognized value of these fungi as sources of single-cell protein with high nutritional value can be tracked back for centuries, on account of their use in fermented food production. Indeed, Rhizopus strains, including those isolated from fermented foods, and Rhizopus oligosporus, a food-grade fungus, were revealed to be composed of up to $50 \%$ protein when cultivated in spent sulphite liquor, thin stillage, or starch processing wastewater (Bankefors et al., 2011; Edebo, 2008; Lennartsson, 2012; Mydland et al., 2007). The biomass protein contents are depending on harvesting, dewatering, and drying methods. Nitrogen concentration in the medium is also believed to affect fungal protein contents (van Leeuwen et al., 2012).

Zygomycetes have long been recognized as valuable sources of lipids, including the unsaturated omega-6 (linoleic and $\gamma$-linolenic acids), omega-7 (palmitoleic acid) and omega-9 (oleic acid), and the saturated C16 (palmitic) and C18 (stearic) fatty acids (Sajbidor et al., 
1988). Long-chain omega-3 polyunsaturated fatty acids, such as eicosapentaenoic acid (EPA) and docosahexaenoic acid (DHA), have also been found in zygomycetes biomass. Maximally, $0.46 \mathrm{~g} / \mathrm{L}$ of EPA and $0.34 \mathrm{~g} / \mathrm{L}$ of DHA were extracted from a cultivation of Mucor sp. in sugar cane molasses and urea, using a $\mathrm{C} / \mathrm{N}$ ratio of 35 (Li et al., 2008). The lipid content was approximately $13 \%$ in Rhizopus sp. grown in spent sulphite liquor, while the oleaginous fungus $M$. circinelloides, grown in thin stillage with addition of extra glycerol, contained 61 \% (Bankefors et al., 2011; Mitra et al., 2012). Due to its nutritional and pharmaceutical importance, $\gamma$-linolenic acid (GLA - C18:3) has sparked a great interest in the science world (Vamvakaki et al., 2010). Many Mucor strains have been observed to produce GLA in their biomass. By using normal conditions supporting lipid production, Mamatha et al. (2010) measured GLA contents of approximately $14 \%$ in the $M$. indicus (rouxii) biomass. Moreover, when cultivated in nitrogen-limited cheese whey, a maximum of $177 \mathrm{mg} / \mathrm{L}$ GLA was produced by a Mucor strain (Vamvakaki et al., 2010), while a maximum of $1.35 \mathrm{~g} / \mathrm{L}$ of GLA was previously reported by Li et al. (2008). Interestingly, Oda et al. (2003) found that lactic acid-producing $R$. oryzae strains contained more $\gamma$-linolenic acid than strains producing fumaric and malic acid. Addition of $\mathrm{CaCO}_{3}$ raised the GLA content to $30 \%$ of the total lipid amount. Single-cell oil production by Mucor circinelloides, rich in $\gamma$-linolenic acid, has already been scaled up to commercial size. In 1985, a process based on $220 \mathrm{~m}^{3}$ continuous stirred-tank reactors was launched, although they are not in use today (Ratledge, 2006). This established a realistic practicability of commercial production of fungal oil, with a potentiality of replacing plant oils as substrate for biodiesel production, or as food.

Lysine, methionine, tryptophan, and threonine are of high relevance for non-ruminants, lysine and methionine usually being the foremost limiting factors in corn-soybean meal diets for swine and poultry, respectively (van Leeuwen et al., 2012). Zygomycetes have been reported 
to produce amino acids, and for instance biomass of $R$. oligosporus grown in thin stillage contained lysine $(1.8 \%)$, tryptophan $(0.3 \%)$, threonine $(1.5 \%)$, methionine $(1.8 \%)$, calculated as percentage of protein. The amounts of the first three amino acids were comparable to those in soybean meal, but fungal methionine content was significantly higher (van Leeuwen et al., 2012). Other amino acids, including arginine, aspartic acid, cysteine, phenylalanine, glutamic acid, histidine, isoleucine, leucine, lysine, proline, serine, tyrosine, and valine, were also present in relevant amounts in Rhizopus biomass (Edebo, 2008; van Leeuwen et al., 2012).

Another remarkable characteristic of the composition of zygomycetes is the high concentration of chitosan in their cell walls. In $R$. oryzae, it amounts to $42 \%$ of the total cell mass (Hjorth, 2005; Lennartsson, 2012), and deriving chitosan from these fungi might thus offer an alternative to the chitosan production involving deacetylation of chitin from marine crustacean shells, a by-product of food industries. Deacetylation of crustacean shells is normally conducted through harsh alkaline hydrolysis at high concentration and temperature, which entails long processing time, environmental pollution, and inconsistent physicochemical properties of the produced chitosan (Aranaz et al., 2009). Production of chitosan from zygomycetes under milder controlled conditions could yield a readily available and much more consistent product.

Mucor dimorphism decides the cell wall chitosan content. M. indicus is known to contain more chitosan when grown in filamentous form than in yeast-like form (Lennartsson, 2012). The amount of glucosamine has been extensively used to evaluate the feasibility of chitosan production from zygomycetes fungi. In a Rhizopus strain isolated from Indonesian tempe, cultivated on spent sulphite liquor in an air-lift bioreactor, up to $42 \%$ of its cell envelope 
consisted of glucosamine monomers (Hjorth, 2005; Lennartsson, 2012). Glucosamine levels have furthermore been estimated during co-production of secondary metabolites. Liu et al. (2008) reported that $R$. oryzae biomass cultured in glucose for L-lactic acid production comprised $25 \%$ glucosamine. Ammonia was added to maintain the glucosamine levels in the $R$. oryzae cell wall, without influencing L-lactic acid production. Liao et al. (2008) used manure as carbon and nitrogen source for co-production of fumaric acid and glucosamine, and observed the glucosamine fraction to be $21 \%$ of the $R$. oryzae biomass.

In a world facing forecasts of food-grade protein depletion, zygomycetes will undoubtedly provide a high value alternative to plant proteins and vegetable oils. Its high-value composition of protein, nutritionally relevant lipids, amino acids, and chitosan will certainly promote committed research towards zygomycetes biomass production, which appears particularly promising within a biorefinery concept. The commercial production of single-cell oil from zygomycetes in biorefineries has long been a reality.

\subsection{Applications of zygomycetes cell mass}

In addition to their valuable biomass composition, zygomycetes possess advantages concerning application within feed production. The strains already employed in preparing fermented foods for human consumption are deemed to be GRAS (Generally Regarded As Safe), which significantly reduces the amount of testing required prior to a full-scale process (Lennartsson, 2012). Further, zygomycetes generally contain relatively small amounts of nucleic acids that, due to the uric acid produced when catabolized, are a limiting factor for human or animal consumption (Solomons \& Litchfield, 1983). The pleasant taste and smell of the produced biomass, and its easy separation from the medium, are additional advantages of using these fungi in the feed industry (Lennartsson, 2012). 
Biomass of a Rhizopus isolate from tempe, cultivated in spent sulphite liquor, is currently tested as an ingredient replacing fishmeal in fish feed (Bankefors et al., 2011; Edebo, 2008; Mydland et al., 2007). The aquaculture sector is at present responsible for the consumption of ca. $70 \%$ of the world fishmeal and $90 \%$ of the fish oil production, hence respectively and contributing to being instrumental in over-fishing and subsequent lack of fish for food, particularly in developing countries (Edebo, 2008; Lennartsson, 2012). Zygomycetes biomass might thus represent an alternative to the vast quantities of fishmeal consumed within fish aquaculture. The results so far are promising. The protein concentration is high, the amino acid composition comparable to that of fishmeal, and the proportion of $\mathrm{C} 18$ unsaturated fatty acids, is approximately $60 \%$. Most importantly, carnivorous fish species, such as rainbow trout (Mydland et al., 2007) and Atlantic salmon (Bankefors et al., 2011), fed a diet containing Rhizopus biomass, grew well and had a high palatability, showing only minor differences from fish fed a standard diet. Production of zygomycetes biomass from spent sulphite liquor has already been tested in an airlift bioreactor, a few $\mathrm{m}^{3}$ in size, and production at larger scales are expected in a near future.

The potentiality of chitosan production reinforces the already high value of zygomycetes biomass. The cationic behaviour of chitosan provides this polymer with numerous and unique features, e.g. being nontoxic, biocompatible, biodegradable, haemostatic, analgesic, tumour inhibiting, mucoadhesive, permeation enhancing, anticholesterolemic, antimicrobial, and antioxidative, granting great possibilities within many different industries (Aranaz et al., 2009). Chitosan has held great importance within various fields, e.g. the biomedical field, including wound healing and drug delivery systems, the food industry as a dietary ingredient 
and preservative, waste water treatment, removing water pollutants, and as immobilization support for cells and enzymes in biocatalysis processes (Aranaz et al., 2009).

The first steps towards a commercial scale of zygomycetes biomass production have been taken, using spent sulphite liquor as substrate. The acceptance of the biomass as fish feed has already been confirmed. It is therefore highly conceivable that zygomycetes biomass will be a part of biorefining, as a foundation for feed production.

\section{Conclusions}

The establishment of biorefineries with zygomycetes as central catalysts is undoubtedly promising. Their ability to grow on starch-based and lignocellulose-based substrates opens the possibility of using an array of cost-effective waste materials. Altogether, zygomycetes hold great potential for the establishment of a platform for production of fine chemicals, enzymes, fungal biomass for food purposes, and lipids. Given their versatility regarding fermentation designs, an intensification of zygomycetes research to valorise organic waste materials, and an establishment of biorefineries, using these filamentous fungi in the main core, is expected in a near future.

\section{Acknowledgements}

The authors would like to thank the Swedish Energy Agency and the University of Borås for financial support. 


\section{References}

1. Abe, A., Oda, Y., Asano, K., Sone, T. 2007. Rhizopus delemar is the proper name for Rhizopus oryzae fumaric-malic acid producers. Mycologia, 99, 714-722.

2. Akin, D.E., Slomczynski, D., Rigsby, L.L., Eriksson, K.-E.L. 2002. Retting flax with endopolygalacturonase from Rhizopus oryzae. Text. Res. J., 72, 27-34.

3. Aranaz, I., Mengibar, M., Harris, R., Panos, I., Miralles, B., Acosta, N., Galed, G., Heras, A. 2009. Functional characterization of chitin and chitosan. Curr. Chem. Biol., 3, 203230.

4. Azeke, M.A., Greiner, R., Jany, K.-D. 2011. Purification and characterization of two intracellular phytases from the tempeh fungus Rhizopus oligosporus. J. Food Biochem., 35, 213-227.

5. Bai, D.-M., Li, S.-Z., Liu, Z., Cui, Z.-F. 2008. Enhanced L-(+)-lactic acid production by an adapted strain of Rhizopus oryzae using corncob hydrolysate. Appl. Biochem. Biotechnol., 144, 79-85.

6. Bai, D.-M., Zhao, X.-M., Li, X.-G., Xu, S.-M. 2004. Strain improvement of Rhizopus oryzae for over-production of L(+)-lactic acid and metabolic flux analysis of mutants. Biochem. Eng. J., 18, 41-48.

7. Bankefors, J., Kaszowska, M., Schlechtriem, C., Pickova, J., Brännäs, E., Edebo, L., Kiessling, A., Sandström, C. 2011. A comparison of the metabolic profile on intact tissue and extracts of muscle and liver of juvenile Atlantic salmon (Salmo salar L.) Application to a short feeding study. Food Chem., 129, 1397-1405.

8. Boyce, A., Walsh, G. 2007. Production, purification and application-relevant characterisation of an endo-1,3(4)- $\beta$-glucanase from Rhizomucor miehei. Appl. Microbiol. Biotechnol., 76, 835-841. 
9. Celestino, K., Cunha, R., Felix, C. 2006. Characterization of a $\beta$-glucanase produced by Rhizopus microsporus var. microsporus, and its potential for application in the brewing industry. BMC Biochem., 7, 23.

10. Chou, W.-I., Pai, T.-W., Liu, S.-H., Hsiung, B.-K., Chang, M.D.-T. 2006. The family 21 carbohydrate-binding module of glucoamylase from Rhizopus oryzae consists of two sites playing distinct roles in ligand binding. Biochem. J., 396, 469-477.

11. Damásio, A.R.d.L., Maller, A., Silva, T.M.d., Jorge, J.A., Terenzi, H.F., Polizeli, M.d.L.T.d.M. 2011. Biotechnological potential of alternative carbon sources for production of pectinases by Rhizopus microsporus var. rhizopodiformis. Braz. Arch. Biol. Technol., 54, 141-148.

12. Ding, Y., Li, S., Dou, C., Yu, Y., Huang, H. 2011. Production of fumaric acid by Rhizopus oryzae: role of carbon-nitrogen ratio. Appl. Biochem. Biotechnol., 164, $1461-1467$.

13. Edebo, L. 2008. Zygomycetes for fish feed. World Patent: WO 2008/002231.

14. Fu, Y.-Q., Li, S., Chen, Y., Xu, Q., Huang, H., Sheng, X.-Y. 2010. Enhancement of fumaric acid production by Rhizopus oryzae using a two-stage dissolved oxygen control strategy. Appl. Biochem. Biotechnol., 162, 1031-1038.

15. Fu, Y., Xu, Q., Li, S., Huang, H., Chen, Y. 2009. A novel multi-stage preculture strategy of Rhizopus oryzae ME-F12 for fumaric acid production in a stirred-tank reactor. World J. Microbiol. Biotechnol., 25, 1871-1876.

16. Ghosh, B., Ray, R.R. 2011. Current commercial perspective of Rhizopus oryzae: A review. J. Appl. Sci., 11, 2470-2486.

17. Gibbs, P.A., Seviour, R.J., Schmid, F. 2000. Growth of filamentous fungi in submerged culture: problems and possible solutions. Crit. Rev. Biotechnol., 20, 17-48. 
18. Guo, Y., Yan, Q., Jiang, Z., Teng, C., Wang, X. 2010. Efficient production of lactic acid from sucrose and corncob hydrolysate by a newly isolated Rhizopus oryzae GY18. J. Ind. Microbiol. Biotechnol., 37, 1137-1143.

19. Heskamp, M.L., Barz, W. 1998. Expression of proteases by Rhizopus species during tempeh fermentation of soybeans. Food / Nahrung, 42, 23-28.

20. Hjorth, H. 2005. The cell wall of Rhizopus oryzae: Structure, properties and applications. Ph.D thesis. Gothenburg University, Department of Clinical Bacteriology. Gothenburg, Sweden.

21. Huang, L., Wei, P., Zang, R., Xu, Z., Cen, P. 2010. High-throughput screening of highyield colonies of Rhizopus oryzae for enhanced production of fumaric acid. Ann. Microbiol., 60, 287-292.

22. Ikasari, L., Mitchell, D.A. 1996. Leaching and characterization of Rhizopus oligosporus acid protease from solid-state fermentation. Enzyme Microb. Technol., 19, 171-175.

23. John, R., Nampoothiri, K., Pandey, A. 2007. Fermentative production of lactic acid from biomass: an overview on process developments and future perspectives. Appl. Microbiol. Biotechnol., 74, 524-534.

24. Kareem, S.O., Adebowale, A.A. 2007. Clarification of orange juice by crude fungal pectinase from citrus peel. Nig. Food. J., 25, 130-137.

25. Koutinas, A.A., Malbranque, F., Wang, R., Campbell, G.M., Webb, C. 2007. Development of an oat-based biorefinery for the production of L(+)-lactic acid by Rhizopus oryzae and various value-added coproducts. J. Agric. Food Chem., 55, $1755-$ 1761.

26. Krisch, J., Takó, M., Papp, T., Vágvölgyi, C. 2010. Characteristics and potential use of $\beta$ glucosidases from zygomycetes. in: Current research, technology and education 
topics in applied microbiology and microbial biotechnology, (Ed.) A. Méndez-Vilas, Vol. 2, Formatex Research Center, pp. 891-896.

27. Lennartsson, P.R. 2012. Zygomycetes and cellulose residuals: hydrolysis, cultivation and applications. Ph.D. thesis. Chalmers University of Technology, Department of Chemical and Biological Engineering. Gothenburg, Sweden.

28. Li, N., Deng, Z.-N., Qin, Y.-L., Chen, C.-L., Liang, Z.-Q. 2008. Production of polyunsaturated fatty acids by Mucor recurvus sp. with sugarcane molasses as the carbon source. Food Technol. Biotechnol., 46, 73-79.

29. Liao, W., Liu, Y., Chen, S., Mielenz, J.R., Klasson, K.T., Adney, W.S., McMillan, J.D. 2007. Studying pellet formation of a filamentous fungus Rhizopus oryzae to enhance organic acid production. Appl. Biochem. Biotechnol., 137, 689-701.

30. Liao, W., Liu, Y., Frear, C., Chen, S. 2008. Co-production of fumaric acid and chitin from a nitrogen-rich lignocellulosic material - dairy manure - using a pelletized filamentous fungus Rhizopus oryzae ATCC 20344. Bioresour. Technol., 99, 58595866.

31. Liu, T., Miura, S., Yaguchi, M., Arimura, T., Park, E.Y., Okabe, M. 2006. Scale-up of Llactic acid production by mutant strain Rhizopus sp. MK-96-1196 from $0.003 \mathrm{~m}^{3}$ to 5 $\mathrm{m}^{3}$ in airlift bioreactors. J. Biosci. Bioeng., 101, 9-12.

32. Liu, Y., Liao, W., Chen, S. 2008. Co-production of lactic acid and chitin using a pelletized filamentous fungus Rhizopus oryzae cultured on cull potatoes and glucose. J. Appl. Microbiol., 105, 1521-1528.

33. M'hir, S., Mejri, A., Sifaoui, I., Slama, M.B., Mejri, M., Thonart, P., Hamdi, M. 2012. Improvement of protease production by Rhizopus oryzae $\mathrm{CH} 4$ grown on wheat gluten using response surface technology and its scale-up in a bioreactor. Arch. Appl. Sci. Res., 4, 1110-1116. 
34. Maleki, M.H., Ghanbary, M.A.T., Ranjbar, G.A., Asgharzadeh, A., Lotfi, A. 2011.

Screening of some Zygomycetes strains for pectinase activity. J. Microbiol. Biotechnol. Res., 1, 1-7.

35. Mamatha, S.S., Halami, P.M., Venkateswaran, G. 2010. Identification and characterization of the n-6 fatty acid-producing Mucor rouxii native isolate CFR-G15. Eur. J. Lipid Sci. Technol., 112, 380-389.

36. Millati, R., Edebo, L., Taherzadeh, M.J. 2005. Performance of Rhizopus, Rhizomucor, and Mucor in ethanol production from glucose, xylose, and wood hydrolyzates. Enzyme Microb. Technol., 36, 294-300.

37. Mitra, D., Rasmussen, M.L., Chand, P., Chintareddy, V.R., Yao, L., Grewell, D., Verkade, J.G., Wang, T., van Leeuwen, J. 2012. Value-added oil and animal feed production from corn-ethanol stillage using the oleaginous fungus Mucor circinelloides. Bioresour. Technol., 107, 368-375.

38. Mydland, L.T., Landsverk, T., Zimonia, T., Kiessling, A., Edebo, L., Storebakken, T. 2007. Mycelium biomass from fungi (Rhizopus oryzae) grown on spent sulphite liquor from paper pulp as a protein source for rainbow trout (Oncorhynchus mykiss). Abstract European Aquaculture Society, Istanbul.

39. Oda, Y., Saito, K., Yamauchi, H., Mori, M. 2002. Lactic acid fermentation of potato pulp by the fungus Rhizopus oryzae. Curr. Microbiol., 45, 1-4.

40. Oda, Y., Yajima, Y., Kinoshita, M., Ohnishi, M. 2003. Differences of Rhizopus oryzae strains in organic acid synthesis and fatty acid composition. Food Microbiol., 20, 371375.

41. Pandey, A., Szakacs, G., Soccol, C.R., Rodriguez-Leon, J.A., Soccol, V.T. 2001. Production, purification and properties of microbial phytases. Bioresour. Technol., 77, 203-214. 
42. Peixoto-Nogueira, S., Sandrim, V., Guimarães, L., Jorge, J., Terenzi, H., Polizeli, M. 2008. Evidence of thermostable amylolytic activity from Rhizopus microsporus var rhizopodiformis using wheat bran and corncob as alternative carbon source. Bioprocess Biosyst. Eng., 31, 329-334.

43. Ramachandran, S., Roopesh, K., Nampoothiri, K.M., Szakacs, G., Pandey, A. 2005. Mixed substrate fermentation for the production of phytase by Rhizopus spp. using oilcakes as substrates. Process Biochem., 40, 1749-1754.

44. Ratledge, C. 2006. Microbial production of $\gamma$-linolenic acid. in: Handbook of Functional Lipids, (Ed.) C.C. Akoh, Taylor \& Francis. Boca Raton, USA.

45. Roa Engel, C., Straathof, A., Zijlmans, T., van Gulik, W., van der Wielen, L. 2008. Fumaric acid production by fermentation. Appl. Microbiol. Biotechnol., 78, 379-389. 46. Roa Engel, C.A., van Gulik, W.M., Marang, L., van der Wielen, L.A.M., Straathof, A.J.J. 2011. Development of a low $\mathrm{pH}$ fermentation strategy for fumaric acid production by Rhizopus oryzae. Enzyme Microb. Technol., 48, 39-47.

47. Rodríguez-López, J., Sánchez, A.J., Gómez, D.M., Romaní, A., Parajó, J.C. 2011. Fermentative production of fumaric acid from Eucalyptus globulus wood hydrolyzates. J. Chem. Technol. Biotechnol., DOI: 10.1002/jctb.2729.

48. Roopesh, K., Ramachandran, S., Nampoothiri, K.M., Szakacs, G., Pandey, A. 2006. Comparison of phytase production on wheat bran and oilcakes in solid-state fermentation by Mucor racemosus. Bioresour. Technol., 97, 506-511.

49. Saha, B.C. 2004. Production, purification and properties of endoglucanase from a newly isolated strain of Mucor circinelloides. Process Biochem., 39, 1871-1876.

50. Saito, K., Hasa, Y., Abe, H. 2012. Production of lactic acid from xylose and wheat straw by Rhizopus oryzae. J. Biosci. Bioeng., 114, 166-169. 
51. Saito, K., Saito, A., Ohnishi, M., Oda, Y. 2004. Genetic diversity in Rhizopus oryzae strains as revealed by the sequence of lactate dehydrogenase genes. Arch. Microbiol., $182,30-36$.

52. Sajbidor, J., Certík, M., Dobroňová, S. 1988. Influence of different carbon sources on growth, lipid content and fatty acid composition in four strains belonging to Mucorales. Biotechnol. Lett., 10, 347-350.

53. Shimonaka, A., Koga, J., Baba, Y., Nishimura, T., Murashima, K., Kubota, H., Kono, T. 2006. Specific characteristics of family 45 endoglucanases from Mucorales in the use of textiles and laundry. Biosci., Biotechnol., Biochem., 70, 1013-1016.

54. Shuvaeva, G., Sysoeva, M. 2010. Xylanase of the micromycete Rhizopus var. microsporus 595: preparation, structural and functional characteristics, and application. Appl. Biochem. Microbiol., 46, 641-647.

55. Solomons, G.L., Litchfield, J.H. 1983. Single cell protein. Crit. Rev. Biotechnol., 1, 21-58.

56. Sues, A., Millati, R., Edebo, L., Taherzadeh, M.J. 2005. Ethanol production from hexoses, pentoses, and dilute-acid hydrolyzate by Mucor indicus. FEMS Yeast Res., 5, 669-676.

57. Taherzadeh, M.J., Fox, M., Hjorth, H., Edebo, L. 2003. Production of mycelium biomass and ethanol from paper pulp sulfite liquor by Rhizopus oryzae. Bioresour. Technol., 88, 167-177.

58. Takii, Y., Ikeda, K., Sato, C., Yano, M., Sato, T., Konno, H. 2005. Production and characterization of $\beta$-glucosidase from Rhizopus oryzae MIBA348. J. Biol. Macromol., 5, 11-16.

59. Thongchul, N., Navankasattusas, S., Yang, S.-T. 2010. Production of lactic acid and ethanol by Rhizopus oryzae integrated with cassava pulp hydrolysis. Bioprocess Biosyst. Eng., 33, 407-416. 
60. Vamvakaki, A.-N., Kandarakis, I., Kaminarides, S., Komaitis, M., Papanikolaou, S. 2010. Cheese whey as a renewable substrate for microbial lipid and biomass production by Zygomycetes. Eng. Life Sci., 10, 348-360.

61. van Leeuwen, J., Rasmussen, M.L., Sankaran, S., Koza, C.R., Erickson, D.T., Mitra, D., Jin, B. 2012. Fungal treatment of crop processing wastewaters with value-added coproducts. in: Sustainable Bioenergy and Bioproducts, (Eds.) K. Gopalakrishnan, R.C. Brown, Springer London. London, pp. 13-44.

62. Vattem, D.A., Shetty, K. 2002. Solid-state production of phenolic antioxidants from cranberry pomace by Rhizopus oligosporus. Food Biotechnol., 16, 189-210.

63. Vially, G., Marchal, R., Guilbert, N. 2010. L (+) Lactate production from carbohydrates and lignocellulosic materials by Rhizopus oryzae UMIP 4.77. World J. Microbiol. Biotechnol., 26, 607-614.

64. Wikandari, R., Millati, R., Lennartsson, P., Harmayani, E., Taherzadeh, M. 2012. Isolation and characterization of Zygomycetes fungi from tempe for ethanol Production and biomass applications. Appl. Biochem. Biotechnol., DOI: 10.1007/s12010-012-9587-x.

65. Wu, X., Jiang, S., Liu, M., Pan, L., Zheng, Z., Luo, S. 2011. Production of L-lactic acid by Rhizopus oryzae using semicontinuous fermentation in bioreactor. J. Ind. Microbiol. Biotechnol., 38, 565-571.

66. Xu, Q., Li, S., Fu, Y., Tai, C., Huang, H. 2010. Two-stage utilization of corn straw by Rhizopus oryzae for fumaric acid production. Bioresour. Technol., 101, 6262-6264. 67. Yao, W., Wu, X., Zhu, J., Sun, B., Miller, C. 2010. Utilization of protein extract from dairy manure as a nitrogen source by Rhizopus oryzae NRRL-395 for L-lactic acid production. Bioresour. Technol., 101, 4132-4138. 
68. Yegin, S., Fernandez-Lahore, M., Jose Gama Salgado, A., Guvenc, U., Goksungur, Y., Tari, C. 2011. Aspartic proteinases from Mucor spp. in cheese manufacturing. Appl. Microbiol. Biotechnol., 89, 949-960.

69. Yen, H.-W., Lee, Y.-C. 2010. Production of lactic acid from raw sweet potato powders by Rhizopus Oryzae immobilized in sodium alginate capsules. Appl. Biochem. Biotechnol., 162, 607-615.

70. Zhang, J., Henriksson, H., Szabo, I., Henriksson, G., Johansson, G. 2005. The active component in the flax-retting system of the zygomycete Rhizopus oryzae sb is a family 28 polygalacturonase. J. Ind. Microbiol. Biotechnol., 32, 431-438.

71. Zhang, Z., Jin, B., Kelly, J. 2008. Production of L(+)-lactic acid using acid-adapted precultures of Rhizopus arrhizus in a stirred tank reactor. Appl. Biochem. Biotechnol., 149, 265-276.

72. Zhang, Z.Y., Jin, B., Kelly, J.M. 2007. Production of lactic acid from renewable materials by Rhizopus fungi. Biochem. Eng. J., 35, 251-263.

73. Zhou, H., Lu, W., Wen, J., Ma, L. 2009. Kinetic analysis of $11 \alpha$-hydroxylation of steroids by Rhizopus nigricans. J. Mol. Catal. B: Enzym., 56, 136-141.

74. Zhou, Z., Du, G., Hua, Z., Zhou, J., Chen, J. 2011. Optimization of fumaric acid production by Rhizopus delemar based on the morphology formation. Bioresour. Technol., 102, 9345-9349.

75. Žnidaršič, P., Komel, R., Pavko, A. 1998. Studies of a pelleted growth form of Rhizopus nigricans as a biocatalyst for progesterone $11 \alpha$-hydroxylation. J. Biotechnol., 60, 207216. 
Table 1: Recent insights on L-lactic acid production by Rhizopus cells.

\begin{tabular}{|c|c|c|c|c|c|c|}
\hline \multicolumn{7}{|c|}{ Free cells } \\
\hline $\begin{array}{c}\text { Microorganism/ } \\
\text { Morphology* }\end{array}$ & Medium & Mode of Operation & $\begin{array}{l}\text { L-LA } \\
(g / L)\end{array}$ & $\begin{array}{c}P^{a} \\
(g / L / h)\end{array}$ & $Y^{b}(g / g)$ & Reference \\
\hline \multirow{3}{*}{ R. oryzae CGMCC 2681} & Sucrose $(120 \mathrm{~g} / \mathrm{L})$ & \multirow{3}{*}{$\mathrm{EF}$} & 98 & 1.02 & 0.81 & \multirow{3}{*}{$\begin{array}{l}\text { Guo et al. } \\
\text { (2010) }\end{array}$} \\
\hline & Glucose $(160 \mathrm{~g} / \mathrm{L})$ & & 115 & 1.60 & 0.81 & \\
\hline & Glucose + Xylose 1:1 (80 g/L) & & 66 & 0.91 & 0.81 & \\
\hline $\begin{array}{l}\text { R. oryzae BCRC } 33071 \\
\text { pellet }\end{array}$ & \multirow{4}{*}{ Sweet potato starch $(60 \mathrm{~g} / \mathrm{L})$} & \multirow{4}{*}{5 L CSTR batch } & 43 & 1.23 & 0.72 & \multirow{4}{*}{$\begin{array}{c}\text { Yen and Lee } \\
\text { (2010) }\end{array}$} \\
\hline cotton-like floc & & & 25 & 0.82 & 0.42 & \\
\hline filamentous & & & 41 & 0.48 & 0.69 & \\
\hline pellet & & & 36 & 1.14 & 0.59 & \\
\hline$R$. oryzae adapted HM11 & Corncob hydrolysate $(97 \mathrm{~g} / \mathrm{L})$ & 5 L CSTR batch & 77 & 0.99 & 0.80 & $\begin{array}{l}\text { Bai et al. } \\
(2008)\end{array}$ \\
\hline \multirow{3}{*}{ R. oryzae NRRL 395} & Glucose $(\sim 70 \mathrm{~g} / \mathrm{L})$ & \multirow{3}{*}{$\mathrm{EF}$} & 22 & 0.43 & 0.31 & \multirow{3}{*}{$\begin{array}{c}\text { Thongchul et } \\
\text { al. (2010) }\end{array}$} \\
\hline & $\begin{array}{l}\mathrm{HCl} \text { treated cassava pulp hydrolysate (- } \\
\qquad 70 \mathrm{~g} / \mathrm{L} \text { sugars) }\end{array}$ & & 7 & 0.16 & 0.09 & \\
\hline & $\begin{array}{l}\text { Enzyme treated cassava pulp hydrolysate } \\
\qquad(-70 \mathrm{~g} / \mathrm{L} \text { sugars })\end{array}$ & & 17 & 0.29 & 0.24 & \\
\hline \multirow{2}{*}{ R. oryzae UMIP 4.77 pellet } & Glucose $(<20 \mathrm{~g} / \mathrm{L}$ residual $)$ & 4 L CSTR fed-batch & 73 & 2.37 & 0.86 & \multirow{4}{*}{$\begin{array}{l}\text { Vially et al. } \\
\text { (2010) }\end{array}$} \\
\hline & Xylose (120 g/L) & \multirow{3}{*}{4 L CSTR batch } & 8 & 0.41 & 0.64 & \\
\hline filamentous & Hemicelluloses (50 g/L $71 \%$ xylose) & & 10 & 0.27 & 0.26 & \\
\hline not reported & Cellulosic material $(100 \mathrm{~g} / \mathrm{L})$ & & 24 & 0.50 & 0.28 & \\
\hline R. oryzae NRRL 395 pellet & Glucose $(105 \mathrm{~g} / \mathrm{L})$ & \multirow{3}{*}{$\mathrm{EF}$} & 57 & 1.87 & 0.56 & \multirow{3}{*}{$\begin{array}{l}\text { Yao et al. } \\
\text { (2010) }\end{array}$} \\
\hline pellet and cotton-like & $+30 \%$ crude protein & & 50 & 0.77 & 0.43 & \\
\hline clump & $+0.42 \mathrm{~g} / \mathrm{L} \mathrm{N}$ protein hydrolysates & & $56-59$ & - & $0.53-0.56$ & \\
\hline R. oryzae AS3.819 pellet & $\begin{array}{c}\text { Glucose }(120 \mathrm{~g} / 1+100 \mathrm{~g} / \mathrm{L} \text { feeding } \\
\text { medium })\end{array}$ & $\begin{array}{c}\text { EF } 20 \text { cycle batch } \\
7 \text { L CSTR } 25 \text { cycle batch }\end{array}$ & $\begin{array}{l}64-95 \\
71-104\end{array}$ & $\begin{array}{c}- \\
2.20-3.90\end{array}$ & $\begin{array}{c}0.79-0.9 \\
-\end{array}$ & $\begin{array}{l}\text { Wu et al. } \\
\text { (2011) }\end{array}$ \\
\hline R. oryzae NBRC 5378 & $\begin{array}{l}\text { Wheat straw }(50 \mathrm{~g} / \mathrm{L}-12 \% \text { cellulose; } \\
41 \% \text { hemicellulose })\end{array}$ & $1 \mathrm{~L} \mathrm{CSTR}$ & 6 & 0.06 & 0.23 & $\begin{array}{l}\text { Saito et al. } \\
\text { (2012) }\end{array}$ \\
\hline
\end{tabular}

Nomenclature: * - when available; ${ }^{\mathrm{a}}$ L-lactic acid productivity; ${ }^{\mathrm{b}}$ L-lactic acid yield; EF - Erlenmeyer Flasks;

CSTR - Continuous-Stirred Tank Reactor. 
Table 2: Recent insights on fumaric acid production by Rhizopus strains, using glucose and lignocellulosic materials as substrates.

\begin{tabular}{|c|c|c|c|c|c|c|}
\hline $\begin{array}{l}\text { Microorganism } \\
\text { /Morphology* }\end{array}$ & Medium & $\begin{array}{c}\text { Bioreactor } / \mathbf{O} \\
\text { peration } \\
\text { mode }\end{array}$ & $\begin{array}{l}\text { FA } \\
(\mathrm{g} / \mathrm{L})\end{array}$ & $\begin{array}{l}P^{a} \\
(g / L / h)\end{array}$ & $Y^{b}(g / g)$ & Reference \\
\hline $\begin{array}{l}\text { R. oryzae ATCC } \\
\text { 20344/Pellet form }\end{array}$ & $\begin{array}{c}\text { Glucose }+ \text { Acid } \\
\text { hydrolysate of } \\
\text { manure fibre }(100 \\
\mathrm{g} / \mathrm{L})\end{array}$ & 1 L CSTR/Batch & 31 & 0.32 & 0.31 & Liao et al. (2008) \\
\hline \multirow{2}{*}{$\begin{array}{l}\text { Mutant } R \text {. oryzae ZJU11 } \\
\text { from ZD-35 }\end{array}$} & \multirow{2}{*}{ Glucose $(85 \mathrm{~g} / \mathrm{L})$} & $\mathrm{EF}$ & 57 & 0.48 & 0.68 & \multirow{2}{*}{ Huang et al. (2010) } \\
\hline & & $5 \mathrm{~L}$ CSTR/Batch & 41 & 0.37 & 0.48 & \\
\hline $\begin{array}{l}\text { Mutant } R \text {. oryzae ME-F12 } \\
\text { from ATCC } 20344\end{array}$ & $\begin{array}{c}\text { Corn straw } \\
\text { hydrolysate }(\text { Glucose } \\
(80 \mathrm{~g} / \mathrm{L})) \\
\end{array}$ & $\mathrm{EF}$ & 28 & 0.33 & 0.35 & Xu et al. (2010) \\
\hline $\begin{array}{l}\text { Mutant } R \text {. oryzae ME-F12 } \\
\text { from ATCC } 20344\end{array}$ & Glucose $(100 \mathrm{~g} / \mathrm{L})$ & 7 L CSTR & 56 & 0.70 & 0.54 & Fu et al. (2010) \\
\hline $\begin{array}{l}\text { R. arrhizus DSM } 5772 \\
\text { /Pellet form }\end{array}$ & $\begin{array}{l}\text { Eucalyptus globulus } \\
\text { wood hydrolysate } \\
\text { (Glucose }(23.39 \mathrm{~g} / \mathrm{L}))\end{array}$ & $2 \mathrm{~L} \mathrm{CSTR/Batch}$ & 10 & 0.43 & 0.44 & Rodríguez-López et al. (2011) \\
\hline
\end{tabular}

Nomenclature: * when available; ${ }^{a}$ Fumaric acid productivity; ${ }^{b}$ Fumaric acid yield; EF - Erlenmeyer Flasks;

CSTR - Continuous-Stirred Tank Reactor. 
Table 3: Overview of the diversity of enzymes produced by Zygomycetes fungi in submerged $(\mathrm{SbmF})$ as well as solid-state fermentation (SSF), using a wide range of substrates.

\begin{tabular}{|c|c|c|c|c|}
\hline Microorganism & Medium & $\begin{array}{l}\text { Culture mode } \\
\text { /Bioreactor }\end{array}$ & Enzyme & Reference \\
\hline $\begin{array}{l}\text { R. microsporus var. } \\
\text { rhizopodiformis }\end{array}$ & $\begin{array}{l}\text { wheat bran }+ \text { corn cobs }+ \text { starch }+ \\
\text { saline solution }\end{array}$ & SSF & Amylase & Peixoto-Nogueira et al. (2008) \\
\hline $\begin{array}{l}\text { Mucor circinelloides } \\
\text { NRRL } 26519\end{array}$ & lactose, cellulose, Sigmacell 50 & $\mathrm{SbmF} / \mathrm{EF}$ & Cellulase system & Saha (2004) \\
\hline $\begin{array}{l}\text { R. microsporus var. } \\
\text { microsporus }\end{array}$ & chitin, xylan, cellulose & $\mathrm{SbmF} / \mathrm{EF}$ & Endoglucanase & Celestino et al. (2006) \\
\hline R. oryzae MIBA348 & wheat bran & $\mathrm{SSF} / \mathrm{EF}$ & $\beta$-glucosidase & Takii et al. (2005) \\
\hline R. oligosporus & cranberry pomace & $\mathrm{SSF} / \mathrm{EF}$ & $\beta$-glucosidase & Vattem and Shetty (2002) \\
\hline $\begin{array}{l}\text { Rhizopus var. microsporus } \\
595\end{array}$ & $\begin{array}{c}\text { wheat bran } \\
\text { xylose }\end{array}$ & $\begin{array}{c}\text { SSF/Thermostat } \\
\text { SbmF/EF }\end{array}$ & Xylanase & Shuvaeva and Sysoeva (2010) \\
\hline R. oryzae NRRL 29086 & citrus pectin & SbmF/14 L CSTR & Polygalacturonase & Zhang et al. (2005) \\
\hline R. oryzae NRRL 29086 & pectin & SbmF/100 L fermenter & Endopolygalacturonase & Akin et al. (2002) \\
\hline R. oligosporus ACM 145F & rice bran & $\mathrm{SSF} / \mathrm{EF}$ & Protease & Ikasari and Mitchell (1996) \\
\hline R. oryzae $\mathrm{CH} 4$ & wheat gluten, starch & SbmF/CSTR & Protease & M'hir et al. (2012) \\
\hline R. nigricans ATTC $6227 b$ & progesterone & $\mathrm{SbmF} / \mathrm{EF}$ & $11 \alpha$-hydroxylase & Žnidaršič et al. (1998) \\
\hline R. nigricans $\mathrm{Tj} 108$ & $16,17 \alpha$-epoxyprogesterone & $\mathrm{SbmF} / \mathrm{EF}$ & $11 \alpha$-hydroxylase & Zhou et al. (2009) \\
\hline $\begin{array}{c}\text { Mucor racemosus NRRL } \\
1994\end{array}$ & wheat bran + sesame oil cake & $\mathrm{SSF} / \mathrm{EF}$ & Phytase & Roopesh et al. (2006) \\
\hline R. oryzae NRRL 1891 & $\begin{array}{l}\text { coconut oil cake }+ \text { sesame oil } \\
\text { cake }\end{array}$ & $\mathrm{SSF} / \mathrm{EF}$ & Phytase & Ramachandran et al. (2005) \\
\hline $\begin{array}{l}\text { R. microsporus var. } \\
\text { oligosporus }\end{array}$ & rice flour & $\mathrm{SbmF} / \mathrm{EF}$ & Phytase & Azeke et al. (2011) \\
\hline
\end{tabular}

Nomenclature: EF - Erlenmeyer Flasks; CSTR - Continuous-Stirred Tank Reactor. 
Fig. 1: Overall scheme of a zygomycetes-based biorefinery, illustrating the alternative feedstock inputs as well as the product outputs, including metabolites, enzymes, and potential cell mass applications. 